\title{
Exploring how a travel script can inform commuting decisions
}

\author{
E. Mbabazi, G. Walker \& C. J. Brown \\ Heriot Watt University, UK
}

\begin{abstract}
With road transport contributing about one-fifth of the European Union's total carbon dioxide emissions, a complementary approach of both hard and soft interventions is necessary to reduce this. In the past, economic rationality assumptions regarding decision making have dominated transport policy. More recently, there has been a growing recognition that individuals' negotiation of the social world influences decision making. This qualitative study, therefore, uses the concept of a travel script to explore how agency is exercised within a given structure in making commuting decisions. A travel script can be conceptualized as a mental representation of the individual's knowledgeability of the structures within which they live, and which constrain or afford certain behaviours. The engagement of a travel script may produce different outcomes owing to the saliency of different factors in different situations. The paper firstly discusses transportation policy in the UK from the 1960 s to the present highlighting its underpinnings in economic rationality. Using commuting history narratives of 82 employees in Edinburgh, cohorts based on attaining driving age in the 1970s, 1980s and 1990s are then compared. The data suggests that the 1970s cohort delayed the start of regular car use for commuting compared to the 1980s and 1990s cohorts. More respondents from the 1970s cohort also underwent a period where they broke from regular car use for commuting than the other two cohorts. Key events are identified from the narratives and the travel knowledgeability surrounding these events is identified using content analysis. Analysis of the relationships among these factors is undertaken to identify aspects of the travel script that are made salient, affecting the exercising of agency in the decision making process.

Keywords: travel script, key events, travel knowledgeability, judgement of effort.
\end{abstract}




\section{Introduction}

Reduction of emissions from transport cannot be achieved through improving the environmental performance of transport systems technologies alone. Researchers such as Kohler [1] propose changes in travel behaviour as a complementary measure. These behaviours are underpinned by assumptions, for example, over the last 50 years the transport planning process in the UK has been underpinned by economic rationality assumptions. Individuals have been assumed to make travel decisions based on utility maximisation. Environmental policy in the UK has in the recent past recognised the influence individual's negotiation of the social world on daily decisions and now pays particular attention to developing frameworks that support this. This paper proposes the use of the travel script concept to understand how individuals negotiate their social world and how this impacts on commuting decisions.

\section{Economic rationality in UK transportation policy}

This section presents the structural backdrop against which travel decisions at the time were made. The 1960 s are termed as the "predict and provide" era. The transport planning process then was concerned with welfare and the planning for and availability of transport for all. 15 years on from the end of the second world war, the economy in Britain was growing, petrol rationing had ended, cars were becoming cheaper and the number of licenced vehicles had increased from 4.5 million in 1950 to over 9 million by 1960 (Gunn [2]). The car was no longer viewed as a luxury for middle income people but an agent of personal liberation for ordinary people (Hall [3]). To accommodate the car, the transport strategies of the 50 s and 60 s were primarily aimed at providing motorways and trunk roads to promote car use. The famous Buchanan report [4] warned of the damage historic cities not previously designed for the car would face due to increasing traffic and called for a certain minimum standard for the urban environment. Beyond that standard, economic trade-offs were possible if the town were both financially able and willing to admit more traffic (Hall [3]).

The predict and provide approach to transport planning was fast declining in popularity by the mid-1970s. There was growing concern about the environmental impact of transport and its social significance. A shift away from investment in roads to better management and use of existing resources was proposed. To facilitate this, local governments were reorganised to promote the provision of a co-ordinated and efficient system of public passenger transport. The 1973 fuel crisis rendered the economic assumptions on which this urban transport policy reorganisation was based obsolete (Headicar [5]). With it came worldwide recession, rising inflation, inner city decline and unemployment. Investment in high quality roads and public transport infrastructure was deemed essential to prevent inner city decline (Banister [6]).

In 1979, the newly elected British Conservative government argued that state involvement hindered progress and its policies in the 1980 s relied on the economics principles of the free market. The 1985 Transport Act legislated for 
the deregulation of bus services outside London. More operators entered the market but, in the conurbations, the reduced subsidies, lack of network coordination and instability of service patterns led to a $26 \%$ decline in patronage in the first 5 years (Headicar [5]). With the costs of driving being significantly reduced, and company financing of motoring growing, the 1980s came to be known by some as the era of the motorist. There was a growth in car traffic of $40 \%$ over the decade (Banister [6]).

In 1989, the white paper 'Roads for prosperity' presented the case for expansion of the road network based on a prediction of traffic level increases of between $83 \%$ and $142 \%$ by 2025 (Banister [6]). This was opposed by coalitions of local objectors and national environmental groups. At this time, the sustainable development agenda was gaining prominence in intellectual debates. There was a shift from the implicit assumption that forecast traffic volumes should be catered for whenever possible. Goodwin's [7] "The new Realism" proposed demand management as a key determinant in policy to match traffic demand to supply. The British government signed the convention on climate change at the 1992 Earth Summit, but made no statements regarding the limiting of $\mathrm{CO}_{2}$ emissions from surface transport. The economic slump at the end of the 1980 s, however, presented conditions where there was a need to increase revenues. Fuel duty was increased by $10 \%$ and a fuel duty escalator by at least $3 \%$ till the year 2000 was introduced (Headicar [5]).

The Labour government in 1997 embraced devolution in a bid to strengthen regional decision making. The Scottish Executive was given power to make laws on a range of issues including aspects of transport like the Scottish road network and bus policy. They published their first transport white paper in $2004-$ Scotland's Transport Future. Like the 1998 UK government white paper on transport policy - A new deal for transport- Scotland's Transport Future made a case for a healthy nation through reduction in car use and increases in active modes. The Scottish Government established the Smarter Choices Smarter Places (SCSP) programme in 2008. This covered a range of techniques that encourage people to modify their travel behaviour and which would save them money, help to make them healthier, reduce transport emissions and develop more cohesive communities.

As with previous decades, economic instruments are used to reduce the utility of the car. Public transport is receiving some support through investment but the car culture seems to have become so deeply embedded in society. The SCSP program relies heavily on providing information about alternative modesdrawing again on the fact that rational beings choose the optimum solution based on the information they possess. Today, most people agree that climate change is a problem and that there is a need to adopt more sustainable behaviours, but in daily life activities, this is not the most important value drawn upon when deciding how to act. 


\section{Social factors and soft interventions}

Soft measures such as those proposed in the SCSP program are complementary to the hard measures. Cairns et al. [8] note that soft policy measures offer good value for money and can be effective in facilitating choice to reduce car use if implemented within a supportive policy context. The interest in soft measures demonstrates the recognition that the individual has to act within the social and material structures they inhabit. The focus on information provision, therefore, is insufficient for their success.

Research is in agreement that social psychological factors influence travel behaviour [9-12], as does one's social context [13-15]. Social psychological factors arise out of mental representations. These are informed by our personal or vicarious experience of the wider structural movements such as described in the previous section. The decision making process in travel behaviour can be taxing in terms of both the personal effort to arrive at a decision and also to perform the behaviour. In considering alternatives, people do not seem to be looking for the optimum choice but the satisficing choice-whereby an alternative will be chosen and the decision making process terminated when the alternative meets an acceptable threshold. The interplay of the social psychological variables, situational factors and the personal effort expended in travel decision making needs to be explored further.

\subsection{The travel script concept}

To investigate this interplay, the research draws on the script concept from Schema theory. A schema can be considered as a generic knowledge structure in memory (Graesser and Nakamura [16]). Giddens [17] conceptualises structure as the set of rules and resources existing as memory traces and instantiated in action. Sewell [18] elucidates that structures are the principles that pattern actions and they exist as schemas in the mind and as they are put into practice. In other words, structures exist in the things we know and the way we put them into practice. Schemas affect and direct the perception, storage and activation of information in the world to provide an individual with past experiences and the knowledge about the action for a specific task (Neisser [19]). Schema, hypothesized as a generic structure, may therefore be regarded as a framework or a script. It is against this background that this research aims to explore how a travel script can inform commuting decisions. A travel script can be conceptualised as a mental structure or representation of the individual's knowledgeability of the structures within which they live.

\section{Methodology}

This research is based on interview data from 82 staff of Heriot Watt University and its associated the Research Park, comprised of companies and government agencies, at the Edinburgh campus. The decision to focus on the commute was based on the fact that among Scottish residents, the commute accounted for the 
highest number of trips compared to other purposes of travel. $25 \%$ of the journeys made for commuting purposes and 23\% for shopping purposes in 2008 . In addition, the average commuting distance was 10 miles compared to 4.7 miles for shopping. About $69 \%$ of the commute trips are made by private car; with people aged between 30 and 59 years travelling almost double the distance travelled by 16 to 29 year olds (Scottish Government [20]).

Respondents were contacted by email and only those aged 30 and above were selected. Research shows that one's travel habits start to become established in their 30s (Lanzendorf [21]). Two thirds had children and the rest did not. All respondents noted that they had access to more than one mode of transport to commute to work therefore every respondent had a travel choice to make. The interviews solicited a retrospective narrative asking the respondent to provide a chronological account of their commuting patterns starting with travel to school. Using statistical, network and content analysis, different types of travel choices could start to be explored.

\subsection{Results and discussion}

From the interview transcripts, 2 groups of key events were identified: Mode related and Life cycle related. Mode related key events noted when a respondent:

- Acquired a driving licence (DL)

- Started regular commuting by car (SC)

- Broke from regular commuting by car (Break) and

- Resumed regular commuting by car (S. Break).

The Life cycle events identified were:

- Start of further education (FE)

- Start of first job (FJ)

- Having the first child (FC)

- Moving to their current residence $(\mathrm{MH})$ and

- Moving to their current job (MJ).

\subsubsection{Analysis of mode related events only}

The ages at which the mode related events occurred were compared against the current age of the respondent. The data suggests that the age at which one acquired a driver's licence (Fig. 1) and the age at which one started regular commuting by car (Fig. 2) are positively correlated with the respondents' current age. This seems to indicate that the older you are, the later you got a licence and started to drive.

By visual inspection, 3 cohorts based on when one reached UK legal driving age (17) were formed. The 1970s cohort refers to people who were or turned 17 between 1970 and 1979 . These are respondents who were 52 years and above in 2014. The 1980s and 1990s cohorts are similarly defined with their ages in 2014 being $42-51$ and 41 and below respectively.

$80.5 \%$ of the 1970 s cohort had acquired a driving licence by the end of the following decade compared to $83 \%$ of the 1980 s and $94 \%$ of the 1990 s cohorts obtaining a licence by the end of their preceding decades. Figure 1 shows more 
respondents in the 1970s cohort and a number at the later part of the 1980s cohort acquired their driving licence later than age 22 compared to the rest. Acquiring a driving licence doesn't necessarily mean one will start driving regularly. In fact, figure 2 shows that with each successive decade, fewer people start regular car use after the age of 30 .

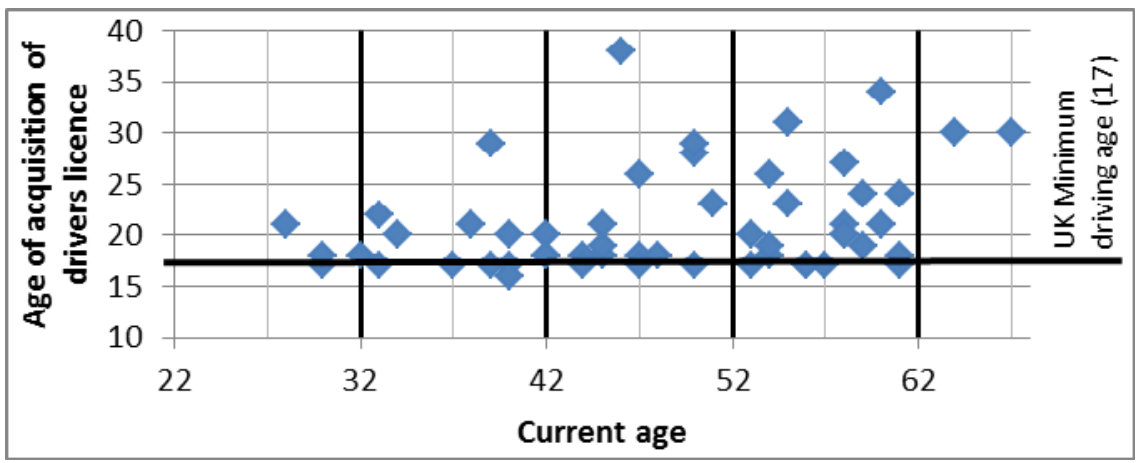

Figure 1: Age of acquiring driving licence against the age of the respondent $(\mathrm{R}=0.310, \mathrm{p}<0.05)$.

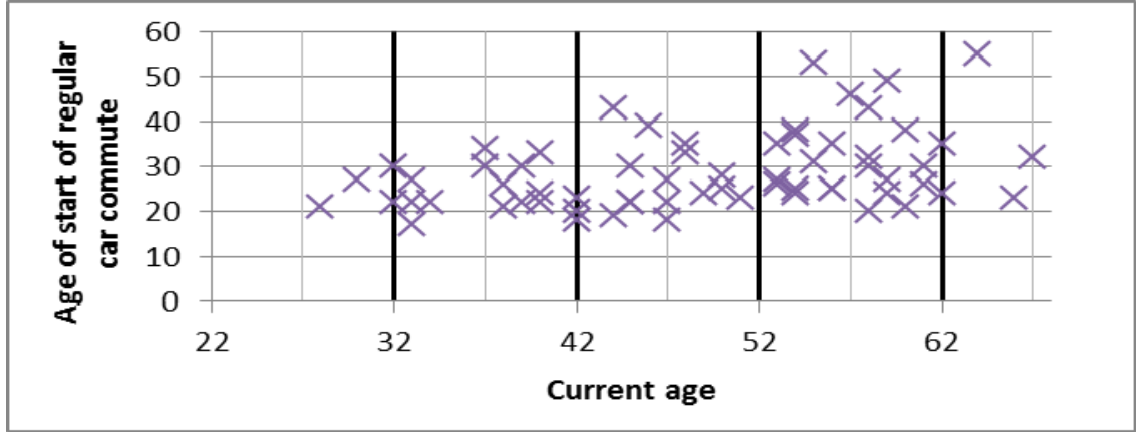

Figure 2: Age at which regular car use was started against age of the respondent $(\mathrm{R}=0.397, \mathrm{p}<0.01)$.

A comparison of the proportions of the respondents from different cohorts who broke from a regular car commute reveals that more of the older respondents took a break from the car. Of those who turned 17 during the $1970 \mathrm{~s}$ and started regular car use, $50 \%$ of them took a break from the car compared to $33 \%$ from the 1980 s and $22 \%$ from the 1990 s cohorts. Of the proportions that broke from car use from each cohort, $63 \%$ of the $1970 \mathrm{~s}$ and $50 \%$ of the $1980 \mathrm{~s}$ and 1990s cohorts have sustained this break to the present. 


\subsubsection{How mode related events relate to life cycle key events}

The differences identified among the cohorts suggest that the travel scripts of these groups also differ. An investigation of the relationship between lifecycle key events and the mode related events for each cohort was therefore undertaken. This paper focusses on the 1970s cohort.

The 1970s cohort's 36 respondents were split along current commute mode: 22 currently using the car as the default commuting mode (Car-default); and 14 using alternative modes like public transport and active travel (Alt-default). Network diagrams were constructed for each group to capture direct changes from one event to another in a given time period. For the 1970s cohort, the time period is 1970 to the present.

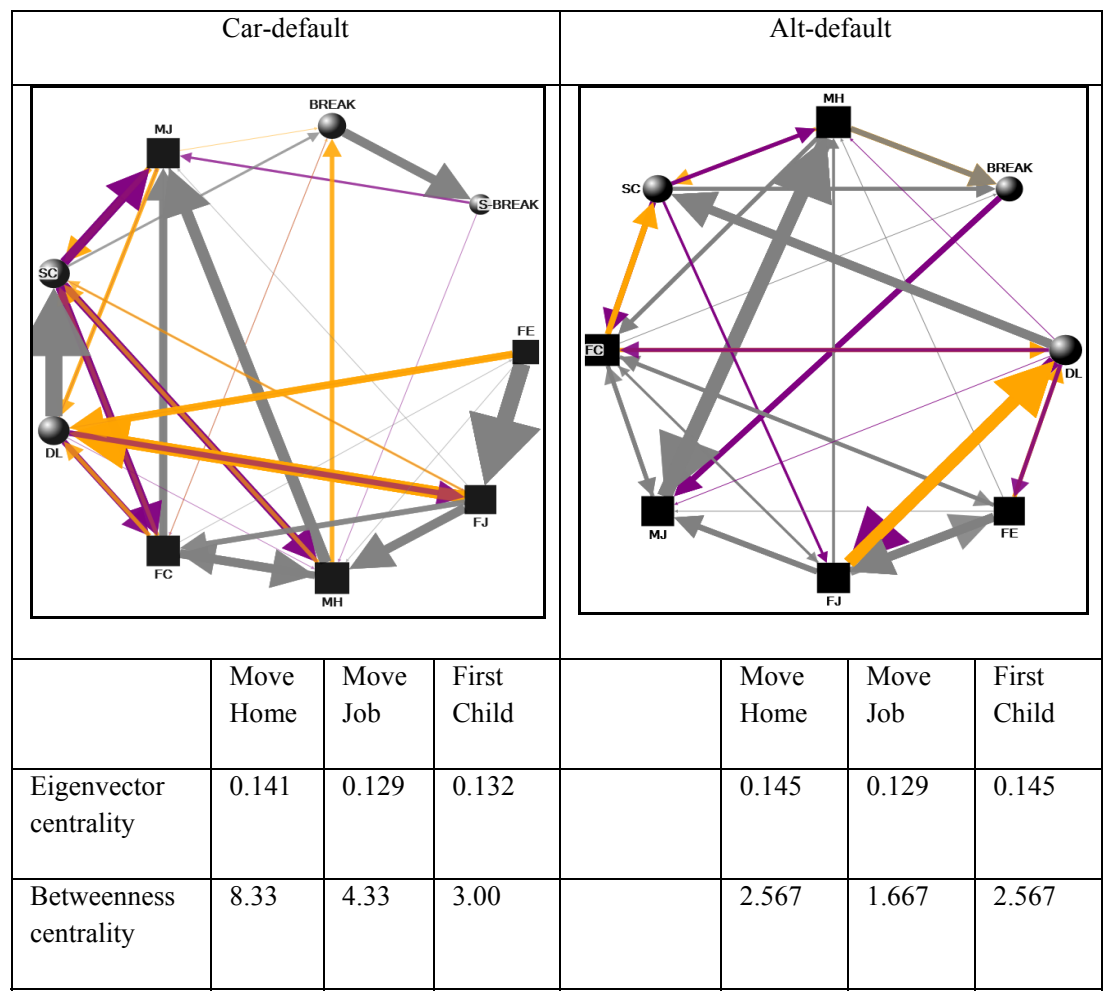

Figure 3: 1970s cohort network comparison.

The density of the networks for both groups is similar implying that cardefault respondents experienced roughly the same key events over the life course as alt-default respondents. Betweenness centrality is a network metric that measures how often a key event connects 2 other key events. The betweenness centrality of the networks reveals that moving to one's current home or job and having the first child are important bridges in both networks. Moving home had 
the highest betweenness centrality for the car-default group, while alt-default group is centred on moving home and first child equally.

Analysis of the specific links from these lifecycle events to the mode related events did not reveal any significant relationship leading to a change in mode for either network. This could imply that these events moderate each other's impact on changes in mode of travel. This is supported by their higher eigenvector centrality meaning that they are connected to other key events with even more connections.

For both groups there are just as many or slightly more people breaking from car use than starting regular car use after moving to the their current home. The network analysis however didn't capture the sequence of events. Data mining of the transcripts showed that in general, the start of further education and the first job occurred earlier in respondent's life course. Having the first child and moving to the current home occurred midway through and moving to the current job occurred closer to the present. Content analysis was used for a more in-depth analysis of the relationship between the changes in mode and the lifecycle events.

\subsubsection{Travel knowledgeability and judgement of effort in the travel script}

Through content analysis, the travel knowledgeability and the judgement of effort that influenced the engagement of the travel script were identified. The travel knowledgeability was conceptualised as the constraints and enablers that made up the structure of a commuting pattern. The earlier discussion on the travel script noted that structures are rules and resources sets existing in the things we know and the way we put them into practice. The experiences of respondents in car-default and alt-default at different lifecycle events are compared. Constraints to and enablers for different modes are identified as "the things we know"; and the mode chosen at that stage as "the way we put them into practice". The constraints include financial constraints, restrictive configuration of public transport and time constraints among others and may be viewed as the rules. The enablers such as availability of a car, public transport and infrastructure for active travel, make up the non-human resources available to commuter.

The proposition that structures are principles that pattern action was important in analysing the judgement of effort to engage in a particular commuting behaviour. Any action that is frequently repeated becomes cast into a pattern reproducible with an economy of effort. When a respondent expresses that they used a particular mode to commute most days, the underlying assumption is that they have arrived at an economy of effort; a balance acceptable to them of all the knowledgeability factors. Some of the feelings expressed about the commute for example "pleasant" or "convenient" can be interpreted as manifestations of economy of effort as well.

Apart from the economy of effort, the analysis reveals situations where the judgement of effort paralysed the engagement of a script:

"It's because I have a very poor sense of direction. I get lost a lot... I'd be dreadful in a car, I'd be lethal in a car." 55 year old mother of 2 
In other situations extra personal effort was expended to ensure the successful engagement of the script:

"In Glasgow I invested in a fairly expensive jacket because it rained all the time, it seemed to be a monsoon but that didn't deter me." 57 year old father of 3

The personal resources identified as part of the commute structure demonstrated this. Personal resources such as physical strength, mastery and emotional commitment were coded as self-efficacy expectations - the expectation that execution of a particular behaviour will produce desired outcomes. Expression of knowledge, more specifically the knowledge of the means to utilise the personal and non-human resources was coded as thresholds, or trade-offs they have to make in order to have an acceptable outcome from their commute.

\subsubsection{Lifecycle events and the travel scripts they influence}

The discussion below considers the knowledgeability and effort expended at each lifecycle event the general order of the events.

At further education, a $47.4 \%$ majority of car-default used active modes to commute while a $55.6 \%$ majority of alt-default commuted by public transport. The modes were enabled by close proximity and availability respectively. In general, the travel script at 'further education' for car-default is similar to that for alt-default. Many respondents faced with financial constraints are unable to run a car and turn to active modes or public transport. Where one had both public transport and active mode choices available to them, poor weather led to a trade off towards public transport. Low efficacy expectations were seen to hold back some respondents from public transport. R51, a 56 year old mother of 2 notes below:

"...I came up to university in Edinburgh after that and walked almost everywhere mainly because I was terrified! I got on the bus going the wrong direction. Edinburgh was a huge city compared to the towns and villages I'd been brought up in and I think I spent at least 2 years in Edinburgh before I started using buses too much at all."

At the start of the first job, the data shows that a number of car-default and alt-default respondents were unable to sustain their active commute at the start of their first job, necessitating their move to public transport. As with the previous lifecycle event, this stage is characterised by financial constraints. Almost half of the 1970s cohort started their first job in early or mid-1970s, around the time of the oil crisis. This could have contributed to the financial constraint. With most people starting their careers, there seemed to be little choice in the location of the job so people endured long public transport commutes as illustrated by R14, a 56 year old father of 3 .

“... in my early career ... I really didn't have a lot of choice in terms of the city that I would end up living in because that was caused by promotion...I was posted to Peterhead ... In those days money was quite tight and a car was a luxury and for the first 3 or 4 months until I could find a home and move the family up, I used a train service from 
Dundee to Aberdeen and then from Aberdeen to Peterhead was the bus service which seemed to be interminably slow, it used to take ages to get to every single little village on the route."

The constraints and enablers to commute when one had their first child are more varied than the previous two life events. Social factors are a major constituent of knowledgeability at this stage. Some women in both groups gave up work for a number of years. For car-default, a slight majority, mostly men, used the bus predominantly due to financial constraints against ownership of a car and the fact that their partners were able to take over running their children to various activities. The $30 \%$ car-default and $40 \%$ alt-default majority who drove at this stage were majorly influenced by the time constraints created by juggling their own activities with their children's. Public transport users at this stage reported having to build patience into their mind-set in order to deal with the time pressures.

The incentive of control of time was more apparent for car-default commuters than alt-default. The car seemed to be viewed as the easiest way to get from work to the children.

“...I think there's definitely a thing about control, when you're in the car you always feel you can go a little bit faster and make it whereas when you're on the bus or the train, you have to just chill and I'm not very good at that..." R78, 56 year old mother of 2

Commute modes for car-default and alt-default commuters started to diverge again at the time of moving to the current home. It would seem that for both, the women who initially gave up work came back into the work force and mostly drove. One of the most pertinent aspects to consider at this lifecycle stage is the motivation for moving to where they did. The main reason expressed was the need to move into what was perceived to be a more ideal environment to raise a family. Financial aspects also played a big role as there are lower house prices in areas on the periphery of Edinburgh than in areas close to Edinburgh city centre. The Edinburgh public transport system is such that all buses are directed towards or away from the city centre. To get to a work place like Heriot Watt campus which is also on the outskirts of the city, a respondent residing at the periphery would have to make at least one connection on the public transport route. Those who worked in the city centre at the time found that public transport worked well for them.

Few still cycled and they expressed strong efficacy expectations in the form of mastery experience. A respondent, for example, noted cycling to their workplace in the city centre because he "...had a habit of doing that". There seems to have been some self-selection regarding settling where one would be enabled to travel the way they would like to. However, none of these respondents expressed mode of travel as a reason for moving to where they did.

The constraints and enablers expressed at the time of moving to the current job are similar to the previous lifecycle event for both car-default and alt-default. This is probably due to the same location issues. Heriot Watt is on the outskirts of the city therefore anyone travelling from the periphery to the Heriot Watt campus faces a long public transport journey with at least one changeover. The 
few respondents in both car-default and alt-default who used active modes at this stage seemed to be incentivising themselves with positive environmental and health attitudes. Alt-default commuters also seem to put more effort in enabling their public transport commute than car-default commuters. This difference in efficacy expectations towards the bus is illustrated below:

"In my heart, I'd like to take the bus every day, but in my head and in my physical laziness I jump in the car because it's so much easier." R78, 56 year old mother of 2 in car-default

"Initially I did think this was far too far out, how am I going to get here and when I put out into, you know you can do these journey planners, it would be $3 / 4$ of an hour and 2 buses but I do like to try and think..." $\mathrm{R} 12,53$ year old mother of 3 in alt-default

The saving on commuting time provided by the car was expressed by both groups as a threshold that tipped the respondents towards the car. For car-default commuters only 2 miles away, the trade-off away from active modes towards the car seems to have been influenced by the time surrounding getting ready for other modes for example, the need to carry things to work or the aversion to arriving at work sweaty necessitating time in the shower. A long distance from the work place necessitating a 2 hour public transport commute was expressed in alt-default as the trade-off towards the car.

\section{Conclusion}

The discussion above demonstrates the influence of knowledgeability in the construction of the travel script. People are aware of the constraints to travel and these do restrict their travel choices. When an individual is faced with a choice between two or more modes, however, the judgement of effort seems even more important for the engagement of the travel script. The perception of economy of effort; the thresholds or trade-offs; and the self-efficacy expectations serve as filters for the commute decision.

Further analysis will aim to tease out the constraints faced at different periods in history; their influence on the travel script and how different groups negotiated these constraints. The 1980s and 1990s cohorts will be analysed and compared with the 1970 s cohort.

\section{References}

[1] Köhler, J., Transport and the environment: Policy and Economic Consideration, Paper for the Foresight Intelligent Infrastructure Systems Project, 2005.

[2] Gunn, S., The Buchanan Report, Environment and the Problem of Traffic in 1960s Britain, Twentieth Century British History, 22(4), pp. 521-542, 2011.

[3] Hall, P., The Buchanan report: 40 years on, Transport, 157(1), pp. 7-14, 2004. 
[4] Buchanan, C. and Crowther, G., Traffic in towns: a study of the long term problems of traffic in urban areas. HMSO, 1963.

[5] Headicar, P., Transport policy and planning in Great Britain. Routledge: London and New York, 2009.

[6] Banister, D., Transport planning. Spon press: New York, 2002.

[7] Goodwin, P., Transport: the new realism. Oxford Transport Studies Unit, 1991.

[8] Cairns, S., Sloman L., Newson, C., Anable, J., Kirkbride, A., and Goodwin, P., Smarter choices-changing the way we travel, Final report of the research project: The influence of soft factor interventions on travel demand, 2004.

[9] Ajzen, I., and Fishbein, M., Attitudes and the Attitude-Behavior Relation: Reasoned and Automatic Processes, European Review of Social Psychology, 11(1), pp. 1-33, 2000.

[10] Ajzen, I., The theory of planned behaviour: reactions and reflections, Psychology \& Health, 26(9), pp. 1113-1127, 2011.

[11] Stern, P.C., Dietz, T., Guagnano, G. A., and Kalof, L., A Value -BeliefNorm Theory of support for Social Movements: The Case of Environmentalism, Human Ecology Review, 6(2), pp. 81-98, 1999.

[12] Triandis, H. C., Interpersonal behavior. Brooks/Cole Pub. Co: California, 1977.

[13] Murtagh, N., Gatersleben, B., and Uzzell, D., Self-identity threat and resistance to change: Evidence from regular travel behaviour, Journal of Environmental Psychology, 32(4), pp. 318-326, 2012.

[14] Griskevicius, V., Cialdini, R. B., and Goldstein, N. J., Social Norms: An underestimated and underemployed lever for managing climate change, International Journal of Sustainable Communication, 3(1), pp. 5-13, 2008.

[15] Axsen, J., Interpersonal influence within car buyers' social networks: observing consumer assessment of plug-in hybrid electric vehicles (PHEVs) and the spread of pro-societal values, University of California, 2010.

[16] Graesser, A. C., and Nakamura, G. V., The Impact of a Schema on Comprehension and Memory, Psychology of Learning and Motivation, 16, pp. 59-109, 1982.

[17] Giddens, A., The constitution of society: introduction of the theory of structuration. University of California Press, 1984.

[18] Sewell, W. H., A Theory of Structure: Duality, Agency, and Transformation, The American Journal of Sociology, 1, p. 1, 1992.

[19] Neisser, U., Cognition and Reality: Principles and Implications of Cognitive Psychology. W. H. Freeman, 1976.

[20] Scottish Government, Scottish Household Survey: Travel Diary 2007/2008, Statistical Bulletin, Trn/2009/4, 2009.

[21] Lanzendorf, M., Key Events and Their Effect on Mobility Biographies: The Case of Childbirth, International Journal of Sustainable Transportation, 4(5), pp. 272-292, 2010. 